\title{
Displacement of Rhipicephalus decoloratus by Rhipicephalus microplus (Acari: Ixodidae) in the Eastern Cape Province, South Africa
}

\author{
N. NYANGIWE ${ }^{1} \cdot$ A. HARRISON ${ }^{2}$ I. G. HORAK ${ }^{3, *}$ \\ ${ }^{1}$ Döhne Agricultural Development Institute, Private Bag X15, Stutterheim, 4930 South Africa, and Department of Conservation \\ Ecology and Entomology, University of Stellenbosch, 7602 South Africa \\ ${ }^{2}$ Mammal Research Institute, Department of Zoology and Entomology, University of Pretoria, Hatfield, Pretoria, 0028, South \\ Africa. \\ ${ }^{3}$ Department of Veterinary Tropical Diseases, Faculty of Veterinary Science, University of Pretoria, Onderstepoort, 0110 South \\ Africa, and Department of Zoology and Entomology, University of the Free State, Bloemfontein, 9301 South Africa. \\ * Author for correspondence: Department of Veterinary Tropical Diseases, Faculty of Veterinary Science, University of Pretoria, \\ Onderstepoort, 0110 South Africa (Tel 027-12-5298371; Fax: 027-12-5298312; E-mail: ivan.horak@up.ac.za)
}

\begin{abstract}
The objective of the study was to establish to what extent the native tick species Rhipicephalus decoloratus had been displaced by the invasive introduced tick, Rhipicephalus microplus at two communally grazed areas in the Eastern Cape Province, South Africa. To this end ticks were collected monthly from 5 cattle over a period of 2 years and from 10 drag-samples of the vegetation over a period of one year at each locality. Whereas 10 years previously only $R$. decoloratus and no $R$. microplus had been recorded in the vicinity of the two sites, $R$. microplus now comprised the bulk of collections at both. Furthermore, significantly greater numbers of $R$. microplus were collected from cattle at both localities during the $2^{\text {nd }}$ year of the survey than during the $1^{\text {st }}(\mathrm{P}<0.05$ and $\mathrm{P}<0.01)$. In addition to 83 instances of intraspecific coupling, there were 17 instances of $R$. microplus males coupled with $R$. decoloratus females. Collections made from cattle and goats on 2 farms close to the study sites revealed that $R$. microplus was present on both host species and that it significantly outnumbered $R$. decoloratus on one of the farms $(\mathrm{P}<0.001)$. R. decoloratus and $R$. microplus larvae as well as larvae exhibiting characteristics of both species were collected from the vegetation.
\end{abstract}

Keywords: cattle, Rhipicephalus decoloratus, Rhipicephalus microplus, displacement, South Africa 


\section{Introduction}

Globally, ticks are considered the most important external parasites of livestock, and they, and the diseases they transmit, represent a severe constraint to successful stock farming in many countries (Jongejan and Uilenberg 2004). Their impact is usually more severe in developing, resource-limited countries than in the developed world (De Castro 1997). In the Eastern Cape Province, South Africa, ticks and tick-borne diseases and their control are considered a major challenge for most small scale cattle farmers (Masika et al. 1997). There are approximately 3.1 million beef cattle in this province, and these comprise nearly a quarter of the total cattle population of South Africa (Anon. 2008), and it is estimated that more than $65 \%$ of these cattle are farmed in communally grazed areas (Anon. 2003). Moreover, the geographical distributions of practically all the economically important tick species that infest livestock in South Africa, include the communally grazed areas of this province (Howell et al. 1978; Horak et al. 2009).

In addition to the threat of infestation by indigenous ticks and the diseases they transmit, cattle in several countries on the African continent are put at risk by the introduction and spread of the Pantropical blue tick, Rhipicephalus microplus. This tick was recorded in the southern coastal belt of South Africa as early as 1908 (Howard 1908), but its actual geographical distribution in this country was only mapped several decades later (Howell et al. 1978). By 2009 Horak et al. (2009) noted that R. microplus was the dominant species in the eastern regions of the Eastern Cape Province, compared to the earlier dominance of the indigenous African blue tick Rhipicephalus decoloratus.

In neighbouring and other countries in Africa Mason and Norval (1980) stated that there was little doubt that $R$. microplus had been introduced into Zimbabwe from Mozambique and that it had subsequently spread westwards along the Zambezi Valley escarpment and southwards towards the Harare (Salisbury) district. Lynen et al. (2008) documented the expansion of its distribution in Tanzania at the expense of $R$. decoloratus compared to that recorded for these ticks by Yeoman and Walker (1967) many years earlier. The first record of R. microplus in West Africa is that of Madder et al. (2007), who reported its presence in Ivory Coast. By 2008 it had almost completely displaced the various indigenous Rhipicephalus (Boophilus) spp. on farms around the village where it had first been detected (Madder et al. 2011). In 2008, a new focus of invasion was detected in the Department of Mono in south-western Benin, 
West Africa and by $2011 R$. microplus had invaded the southern half of that country (Madder et al. 2012; De Clercq et al. 2012). A survey conducted in southern Mozambique, bordering the Kruger National Park in South Africa, in which park only $R$. decoloratus is present (Horak et al. 1992; 2003), yielded only $R$. microplus and no R. decoloratus from cattle and goats sampled at 30 dip-tanks (Horak et al. 2009).

The aims of the present investigation were to establish to what extent the invasive species $R$. microplus had displaced the native $R$. decoloratus in two inland, communally grazed areas to the west of the city of East London in the Eastern Cape Province, South Africa.

\section{Materials and methods}

Study localities (Figure 1A, B)

The Ncerha communal grazing area (33 04'S; $27^{\circ} 34^{\prime} \mathrm{E}$; alt. $197 \mathrm{~m}$ ) lies within the Albany Coastal Belt (Mucina and Rutherford 2006). The most common grass species here are Cynodon dactylon, Digitaria eriantha, Eragrostis plana, Sporobolus fimbriatus, Themeda triandra and Paspalum dilatatum, while common trees include Acacia karoo, Diospyros simmii, Maytetus heterophylle, Grewia occidentalis and Scutia myrtina. The highest mean atmospheric temperatures are recorded in January and February $\left(26^{\circ} \mathrm{C}\right)$ and the lowest in June $\left(13^{\circ} \mathrm{C}\right)$. Average annual rainfall varies between approximately $900 \mathrm{~mm}$ in the hot wet season and $450 \mathrm{~mm}$ in the cool dry season. The spring months tend to be windy while least wind is recorded from January to March.

The Majali communal grazing area (32 $44^{\prime} \mathrm{S}$; $27^{\circ} 31^{\prime} \mathrm{E}$, alt. $\left.609 \mathrm{~m}\right)$ is located in Bhisho Thornveld (Mucina and Rutherford 2006). The most common grass species are Eragrostis plana, Sporobolus africanus and Themeda triandra, while common trees include Acacia karoo, Ehretia rigida, Lippie javanica and Scutia myrtina. The climate varies between a hot-wet season and a cool dry season. The highest mean temperature is recorded in February $\left(26^{\circ} \mathrm{C}\right)$ and the lowest in June $\left(7^{\circ} \mathrm{C}\right)$. Average annual rainfall fluctuates between approximately $900 \mathrm{~mm}$ in the hot wet season and $500 \mathrm{~mm}$ in the cool dry season. 

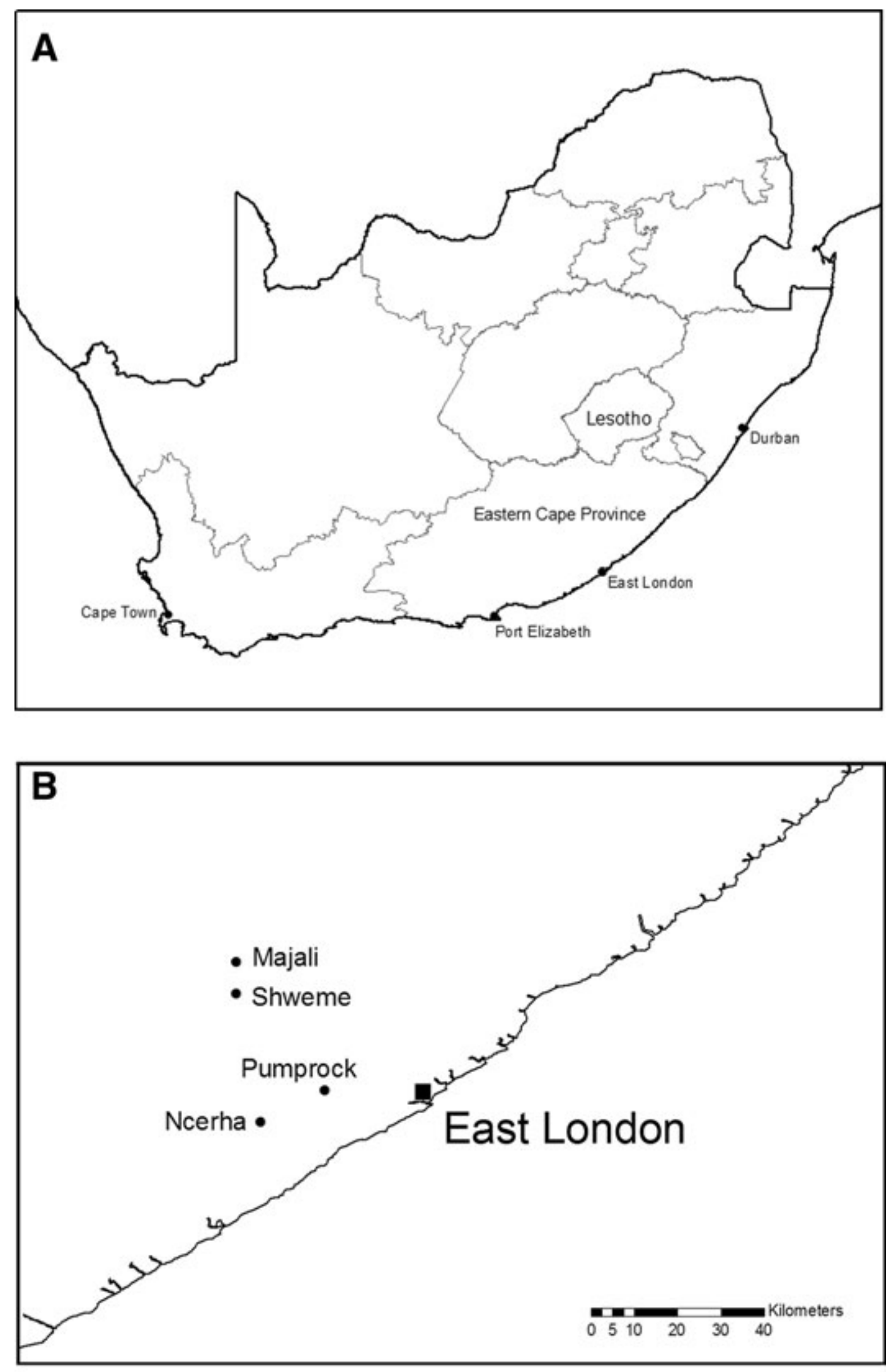

Fig. 1 Four localities in the Eastern Cape Province, South Africa, at which ticks were collected 
Cattle ticks

Adult ticks were collected monthly at both localities from February 2010 until January 2012 from 5 healthy, approximately 2 year-old cattle that had visible tick infestations. Animals were selected from a pool of five different owners. However, the 5 animals varied from month to month due to the nature of the communal grazing set up. Ticks were collected mainly from one side of the animal, including half the head and one ear, but also from the whole of the upper perineum and tail brush. Ticks from each animal were stored in $70 \%$ ethanol in internally labelled vials for later identification and counting. From February 2011 to January 2012 the numbers of male $R$. decoloratus or male $R$. microplus coupled with female ticks were recorded, as were the species of the female ticks with which the males had coupled. Coupling of male ticks with engorged nymphs was also recorded.

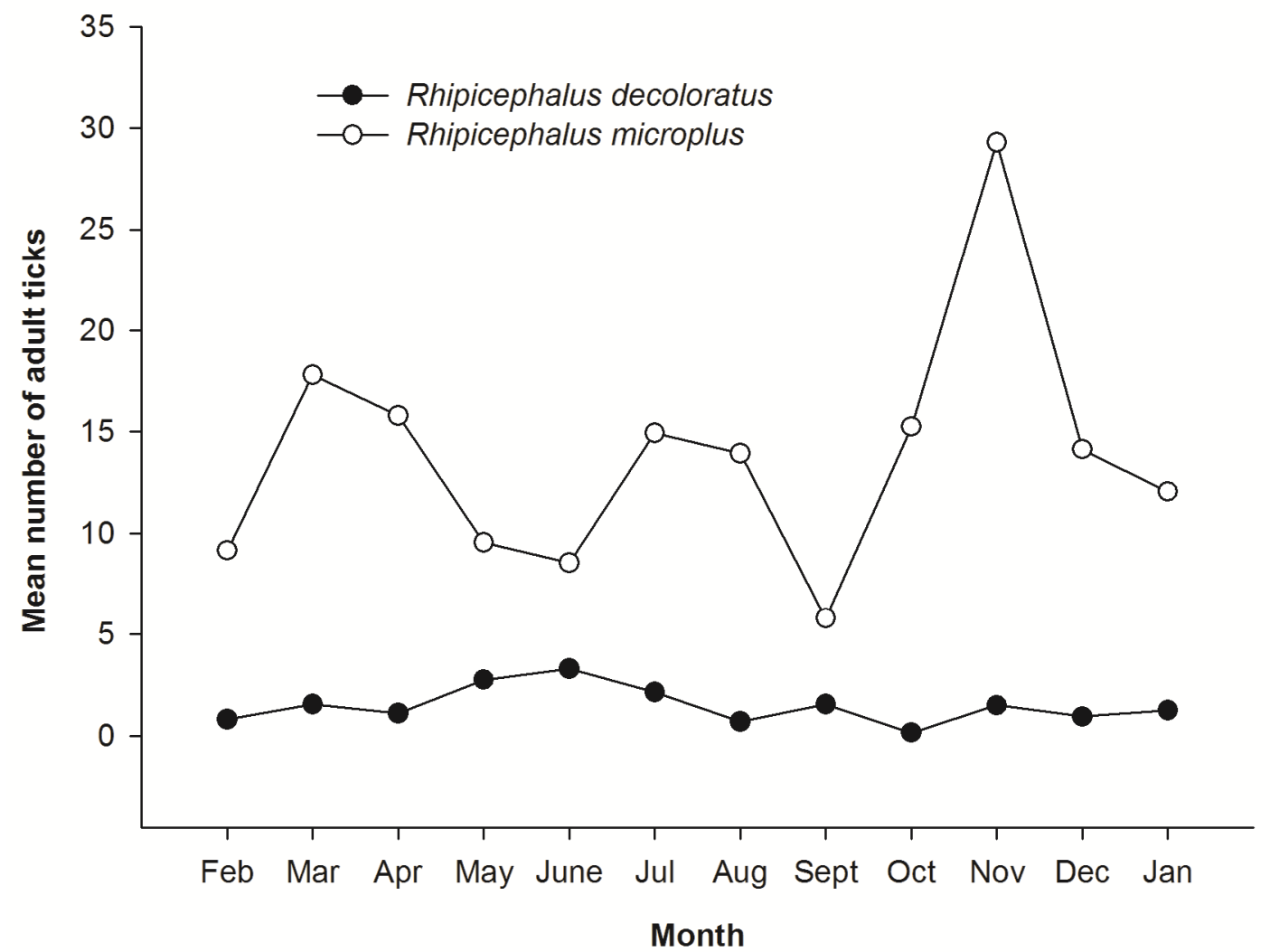

Fig. 2 Seasonal abundance of the adults of R. decoloratus and R. microplus on cattle at two communally grazed localities in the East London District of the Eastern Cape Province, South Africa (years and sites combined)

Because of the proximity of the study sites to each other, and the effect that regular plunge-dipping in the formamidine compound, amitraz, probably had on tick numbers, the mean monthly numbers of adult 
ticks from both localities and over the 2 years of the study, have been separately combined for each species in order to strengthen any pattern of seasonal abundance that may emerge and to enhance the graphic presentation of results (Figure 2).

Questing ticks

Rhipicephalus (Boophilus) spp. larvae questing for hosts on vegetation in the communal grazing areas were collected by drag-sampling as described by Nyangiwe et al. (2011). Ten replicate 100m long drags, approximately 50m apart, were performed monthly for a period of 12 months (February 2011 - January 2012) at both localities. After each drag all ticks on the flannel strips were collected by means of finetipped forceps and stored in 70\% ethanol in internally labeled vials for later identification and counting. Once the larvae present in each of the drag-samples had been identified and counted they were decanted with the alcohol in which they had been preserved into a single large vessel reserved for each of the localities. Larvae were identified using the descriptions provided by Arthur and Londt (1973) for $R$. decoloratus, Londt and Arthur (1975) for R. microplus, and Gothe (1967) for the larvae of both species. To avoid confusion with other Rhipicephalus species the subgenus name, Boophilus has been included whenever reference is made to these ticks at the generic but not at the specific level.

It was only after all the questing larvae had been identified, counted and decanted into a single vessel for each locality that it was realized that the $R$. (Boophilus) spp. group of larvae apparently comprised three entities. These consisted of larvae that were typically $R$. decoloratus or $R$. microplus and larvae that exhibited characters intermediate between the two species. The palps of the latter group of larvae were often upright instead of sloping inwards as for $R$. microplus, the palps were sometimes longer than those of $R$. decloratus or $R$. microplus, but shorter than the palps of Rhipicephalus evertsi evertsi. The scutum of some larvae, that in all other aspects resembled $R$. microplus, was longer and more angular and similar in appearance to that of $R$. decoloratus, and the idiosoma of some of these larvae was oval and not circular as in the case of questing $R$. decoloratus and $R$. microplus larvae.

During the identification of ticks in the individual drag samples the atypical larvae had unfortunately been assigned to either $R$. decoloratus or $R$. microplus depending on their most prominent characteristics. This was done because at the time it had seemed almost impossible that there could be a third $R$. 
(Boophilus) species in South Africa, in which only R. decoloratus and R. microplus are known to be present. In an attempt to rectify this mistake $300 R$. (Boophilus) spp. larvae from each of the vessels reserved for the two localities were re-examined and identified to the best of our ability. The proportions of these larvae belonging to the three groups were used to allocate the remainder of the larvae collected from the vegetation to one of the groups. This procedure made it impossible to separately determine the seasonality of the larvae in the three groups and they have been combined as $R$. (Boophilus) spp., and their seasonality graphically illustrated (Figure 3 ).

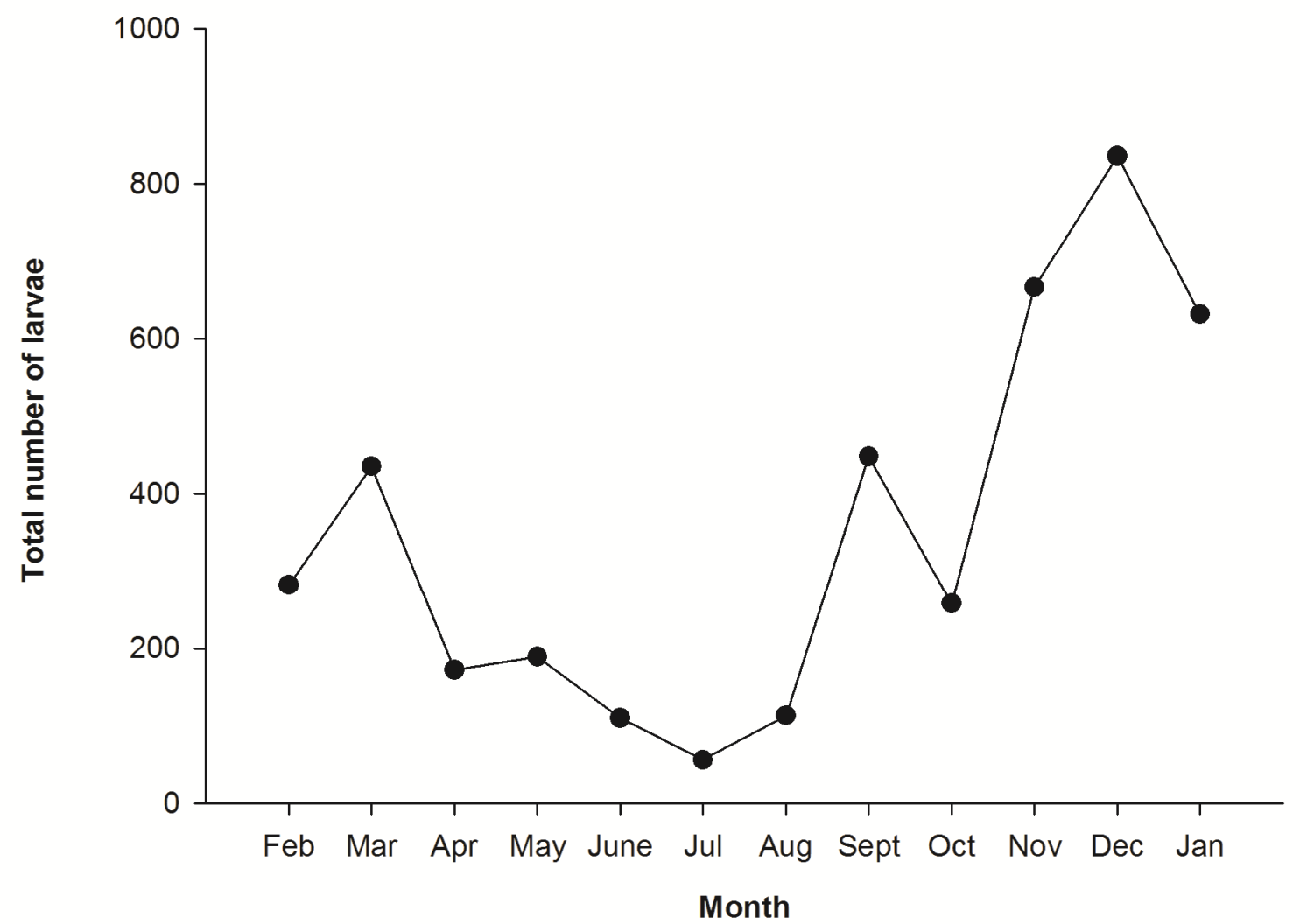

Fig. 3 Seasonal abundance of larvae in the three entities constituting the Rhipicephalus (Boophilus) group combined on vegetation at two communally grazed localities in the East London District of the Eastern Cape Province, South Africa (sites combined)

\section{Additional collections}

Ticks were collected during March and again during September 2011 from five cattle and from five goats on two privately owned farms. One of these farms, 'Pumprock' $\left(33^{\circ} 00^{\prime} \mathrm{S}, 27^{\circ} 42^{\prime} \mathrm{E}\right.$, alt $\left.280 \mathrm{~m}\right)$ was close to the Ncerha communal grazing area, while the other, 'Shweme' ( $32^{\circ} 48^{\prime} \mathrm{S}, 27^{\circ} 31^{\prime} \mathrm{E}$, alt. $\left.522 \mathrm{~m}\right)$ was 
close to the Majali communal grazing area (Figure 1A, B). These collections were made in order to compare the proportional representations of $R$. decoloratus and $R$. microplus on privately owned farms with those on the two communally grazed areas.

Table 1. Total number of ticks in collections $(n=120)$ from cattle and from the vegetation $(n=120)$ within the Ncerha and Mjali communal grazing areas

\begin{tabular}{|c|c|c|c|c|c|c|}
\hline \multirow{2}{*}{ Locality and tick species } & \multicolumn{4}{|c|}{ Collections from cattle $(n=120)$} & \multicolumn{2}{|c|}{ Vegetation collections $(n=120)$} \\
\hline & Males & Females & Total & Number positive & Larvae & Number positive \\
\hline \multicolumn{7}{|c|}{ Ncerha communal grazing area } \\
\hline Rhipicephalus decoloratus & 52 & 207 & 259 & 69 & 252 & \\
\hline Rhipicephalus microplus & 425 & 751 & 1176 & 89 & 603 & \} 114 \\
\hline Rhipicephalus (Boophilus) sp. & 0 & 0 & 0 & 0 & 524 & \\
\hline \multicolumn{7}{|c|}{ Majali communal grazing area } \\
\hline Rhipicephalus decoloratus & 12 & 66 & 78 & 27 & 378 & \\
\hline Rhipicephalus microplus & 578 & 1379 & 1957 & 109 & 1151 & \} 116 \\
\hline Rhipicephalus (Boophilus) sp. & 0 & 0 & 0 & 0 & 1322 & \\
\hline
\end{tabular}

\section{Results}

The total numbers of adult $R$. decoloratus and $R$. microplus collected from cattle and the numbers of larvae of the R. (Boophilus) spp. grouping collected from the vegetation at the Ncerha and Majali communal grazing areas are summarized in Table 1. At both localities $R$. microplus was the dominant species on cattle, while a substantial number of $R$. decoloratus adults were also collected at Ncerha, but not at Majali. More larvae of the three entities within the $R$. (Boophilus) spp. grouping were collected from vegetation at Majali than at Ncerha.

The mean numbers of adult ticks collected from cattle between February 2010 and January 2012 and of $R$. (Boophilus) spp. larvae collected from the vegetation at Ncerha and Majali between February 2011 and January 2012 are summarized in Table 2 . Significantly more adult $R$. decoloratus $(W=35.5, \mathrm{P}<0.01)$ were collected per month from cattle at Ncerha than at Majali, whereas significantly more adult $R$. 
Table 2. Mean number of adult ticks $( \pm \mathrm{SE})$ collected per month from cattle over two years and mean number of larvae $( \pm \mathrm{SE})$ collected per month from vegetation over a single year at Nchera and Majali. Wilcoxon signed rank test statistics $(W)$ for paired monthly differences in the abundance of ticks between sites and associated P-values are presented.

\begin{tabular}{|c|c|c|c|c|c|}
\hline Tick species & Instar & Ncerha & Majali & Test statistic & P-value \\
\hline \multicolumn{6}{|c|}{ Cattle (5 animals per month per site, February 2010 to January 2012) } \\
\hline Rhipicephalus decoloratus & Adult & $10.79 \pm 2.19^{\mathrm{ac}}$ & $3.25 \pm 1.09^{\mathrm{ad}}$ & 35.5 & $\mathrm{P}<0.01$ \\
\hline Rhipicephalus microplus & Adult & $49.00 \pm 13.63^{\mathrm{bc}}$ & $81.54 \pm 11.33^{\text {bd }}$ & 42.0 & $\mathrm{P}<0.01$ \\
\hline \multicolumn{6}{|c|}{ Vegetation (10 drag samples per month, per site, February 2011 to January 2012) } \\
\hline Rhipicephalus (Boophilus) spp. & Larvae & $57.46 \pm 11.40$ & $118.79 \pm 30.09$ & 23.0 & $\mathrm{P}=0.209$ \\
\hline \multicolumn{6}{|c|}{ Values with the same superscript are significantly different } \\
\hline \multicolumn{6}{|l|}{$\mathrm{a}$ and $\mathrm{b}=\mathrm{P}<0.01$} \\
\hline
\end{tabular}

microplus were collected per month from cattle at Majali than at Ncerha (Wilcoxon sign rank tes, $W=$ 42.0, $\mathrm{P}<0.01$ ). In addition, more $R$. microplus than $R$. decoloratus were collected from cattle at both Ncerha $(W=10.0, \mathrm{P}<0.001)$ and Majali $(W=2.0, \mathrm{P}<0.001)$. There was no significant difference between the numbers of $R$. (Boophilus) spp. larvae collected at the two sites.

A comparison of the mean number of ticks collected from cattle per month per year is summarized in Table 3. The numbers of $R$. decoloratus collected monthly during the $1^{\text {st }}$ year of the study were not significantly different from those collected in the $2^{\text {nd }}$ year at either locality. Significantly more $R$. microplus were collected in the second year of the study at both Ncerha $(W=7.0, \mathrm{P}<0.05)$ and Majali $(W=3.0, \mathrm{P}<0.01)$ than in the first year.

Table 3. Mean number of adult ticks $( \pm$ SE) collected monthly from February 2010 and 2011 to January 2011 and 2012 respectively from 5 cattle per site per year at Nchera and Majali. Wilcoxon signed rank test statistics $(W)$ for paired monthly differences in the abundance of ticks between sites and associated P-values are presented. (significant differences are presented in bold).

\begin{tabular}{|c|c|c|c|c|c|}
\hline Site & Tick species & Feb’10-Jan'11 & Feb'11-Jan'12 & Test statistic & P-value \\
\hline & Rhipicephalus decoloratus & $7.42 \pm 2.23$ & $14.17 \pm 3.61$ & 17.5 & $\mathrm{P}=1.378$ \\
\hline & Rhipicephalus microplus & $22.08 \pm 5.79^{\mathrm{a}}$ & $75.92 \pm 24.72^{\mathrm{a}}$ & 7.0 & $\mathrm{P}<0.05$ \\
\hline \multicolumn{6}{|c|}{ Majali } \\
\hline & Rhipicephalus microplus & $45.67 \pm 14.07^{\mathrm{b}}$ & $117.42 \pm 14.07^{\mathrm{b}}$ & 3.0 & $\mathrm{P}<0.01$ \\
\hline
\end{tabular}

Values with the same superscript are significantly different 
Combining the findings at the two localities the observations on coupling and cross-coupling of $R$. decoloratus and $R$. microplus can be summarized as follows. There were 12 instances of $R$. decoloratus males coupled with $R$. decoloratus females, 71 instances of $R$. microplus males coupled with females of the same species, and 17 instances of $R$. microplus males coupled with $R$. decoloratus females. No couplings between $R$. decoloratus males and $R$. microplus females were observed. Furthermore, 13 male R. microplus were found attached adjacent to and clasping engorged nymphs. Upon dissecting 10 of these nymphs, 9 were going to moult to female ticks and the gender of the $10^{\text {th }}$ could not be determined.

The seasonal abundances of adult $R$. decoloratus and $R$. microplus are depicted in Figure 2, and that of larvae in the three entities constituting the $R$. (Boophilus) spp. grouping combined in Figure 3 . No clear pattern of seasonal abundance for adult $R$. decoloratus was evident, and although adults of $R$. microplus appeared to peak in November, this was largely driven by a substantial number of ticks (165) collected from a single animal. Most larvae of the three entities in the $R$. (Boophilus) spp. grouping were present in March and from September to January, while few were collected from June to August.

Table 4. Ticks collected during March and during September 2011 from five cattle and five goats on the farms 'Pumprock' and 'Shweme' close to the Ncerha and Mjali communal grazing areas (see text for two sample Z-test statistics and associated Pvalues).

Total numbers of ticks collected

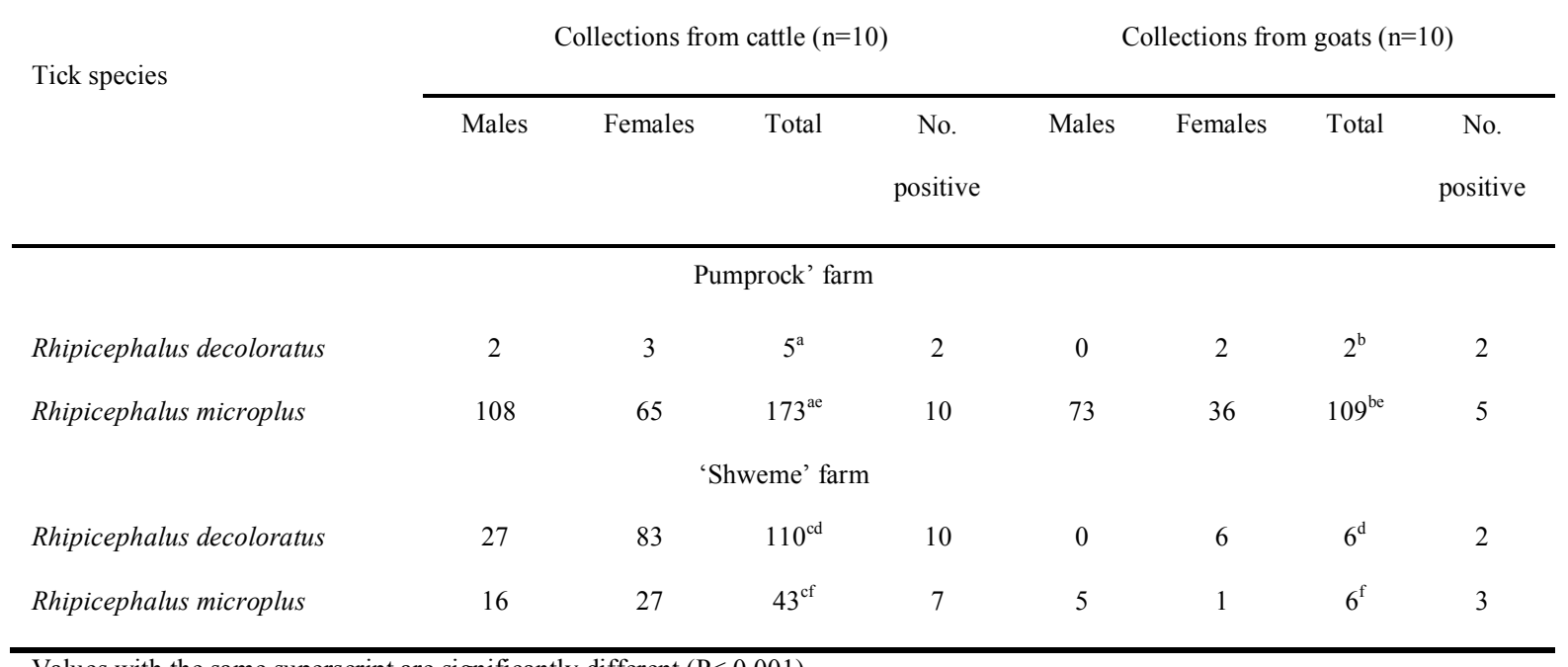

Values with the same superscript are significantly different $(\mathrm{P}<0.001)$

The numbers of adult $R$. decoloratus and $R$. microplus collected from cattle and goats on the farm 'Pumprock', close to the Ncerha community and on the farm 'Shweme', close to the Majali community 
are summarized in Table 4. R. microplus was significantly more abundant than $R$. decoloratus on cattle ( $\mathrm{Z}=-14.43, \mathrm{P}<0.001)$ and goats $(\mathrm{Z}=-11.14, \mathrm{P}<0.001)$ at 'Pumprock', while more $R$. decoloratus than $R$. microplus were present on cattle $(\mathrm{Z}=6.045, \mathrm{P}<0.001)$, but not goats, at 'Swheme'. The numbers of $R$. decoloratus collected from cattle and goats at 'Pumprock' did not differ significantly, most likely because of the few ticks collected there, whereas significantly more $R$. decoloratus were recovered from cattle than from goats at 'Swheme' $(\mathrm{Z}=10.18, \mathrm{P}<0.001)$. More $R$. microplus were collected from cattle than from goats at both sites ('Pumprock', $\mathrm{Z}=4.26, \mathrm{P}<0.001$; 'Swheme', $\mathrm{Z}=5.40, \mathrm{P}<0.001$ ).

\section{Discussion}

The adults of $R$. decoloratus and $R$. microplus collected from cattle could easily be distinguished from each other on their characteristic morphological features, and no aberrations in these features were evident. Questing larvae typical of R. (Boophilus) decoloratus and R. (Boophilus) microplus could also be identified. However, as mentioned above, a large number of $R$. (Boophilus) sp. larvae displayed features characteristic of both species. Consequently, these larvae were designated as belonging to the $R$. (Boophilus) spp. group and could represent hybrids between the two species. Hybrids between Rhicephalus (Boophilus) annulatus and R. (B.) microplus have successfully been reared to adults by Davey and Hilburn (1991). The adults were, however, sterile. It would require laboratory experimentation, outside the scope of this investigation, to determine the viability of the so-called hybrids presently encountered.

Two studies, in which an attempt was made to collect all ticks from kudus (Tragelaphus strepsiceros) and impalas (Aepyceros melampus), shot and processed specifically for this purpose, revealed that for every $R$. decoloratus female there are at least two males, five to six nymphs and 10 to 12 larvae on the same animal (Horak et al. 1992, 2003). There is no reason to believe that this pattern should be otherwise for R. microplus. Consequently, the number of male ticks of both species collected in the present study should have been at least twice that of the number of females. The fact that the number of females recovered outnumbered the number of males suggests that the collections were by no means exhaustive. In addition, when sampling living animals it is virtually impossible to collect all adult ticks of these species from the numerous sites to which they attach. Consequently the numbers of adult $R$. decoloratus 
and R. microplus collected from cattle at both localities do not represent the true burdens of these ticks. Despite this drawback it is evident that considerably more adult $R$. microplus than adult $R$. decoloratus were recovered at both communal grazing areas.

Based on collections of ticks made from cattle over the preceding decades, Howell et al. (1978) mapped the geographical distributions $R$. decoloratus and $R$. microplus in South Africa. At the time, $R$. decoloratus occupied almost the entire eastern region of the Eastern Cape Province while the distribution of R. microplus was patchy and discontinuous. A few years later, Baker et al. (1981) and Baker (1982) mapped a considerably more extensive distribution for $R$. microplus in the eastern region of the Eastern Cape Province. During surveys conducted in 2004 and 2005 it became obvious that the distribution patterns of the two species in this region had reversed and that $R$. microplus was now the dominant species (Horak et al. 2009). The latter authors also suggested that R. microplus was in the process of displacing $R$. decoloratus. In contrast Nyangiwe et al. (2011) reported that although questing larvae of $R$. microplus outnumbered those of $R$. decoloratus on the vegetation of an experimental farm in Döhne Sourveld in the eastern region of the Eastern Cape Province, the ratio between the two species remained more or less stable over a period of 5 years.

Until the fairly recent past $R$. decoloratus seemingly remained the only species present to the immediate west of the city of East London, Eastern Cape Province. Rechav (1982), who collected ticks from cattle in the coastal region approximately $20 \mathrm{~km}$ to the south-west of East London, recovered large numbers of $R$. decoloratus, but no R. microplus. Furthermore, a survey conducted by Horak (1999) along the coast approximately $150 \mathrm{~km}$ to the south-west of East London yielded a small number of $R$. decoloratus, but also no R. microplus. While Mekonnen et al. (2002, 2003), who conducted acaricide resistance studies on ticks collected from cattle in the immediate vicinity of the Nchera and Majali communally grazed areas, also recorded only $R$. decoloratus and no $R$. microplus.

In the light of the present results it would seem that $R$. microplus is a recent introduction into the region immediately to the west of East London and that, as is the case in the more eastern region of the Eastern Cape Province, it is in the process of superseding $R$. decoloratus. Domestic cattle are the most efficient hosts of R. microplus (Mason and Norval 1980). Goats play a lesser, but still significant role (Nyangiwe and Horak 2007; De Matos et al. 2009), and as demonstrated on the farms 'Pumprock' and 'Shweme' in this study. It is thus on cattle and possibly to a lesser extent on goats, purchased in localities 
where $R$. microplus is present, that it has been introduced into the region. However, where in the past displacement was a seemingly slow process, its pace now appears to have accelerated, an observation similar to that reported by Tonnenson et al. (2004) in Limpopo Province, South Africa and Madder et al. (2011) in the Ivory Coast and De Clercq et al. (2012) in Benin.

Judging by the significant increase in numbers at both Majali and Ncerha during the second year of the survey compared to the first, it is also possible that $R$. microplus was being selected for resistance against Amitraz, the acaricide in use at both localities. This eventuality would further enhance its potential as an invasive species. The most recently published results of acaricide resistance studies in the eastern region of the Eastern Cape Province would seem to support this possibility. Acaride resistance tests conducted on $R$. decoloratus on two communally grazed areas close to Ncerha and Majali revealed no resistance to amitraz (Mekonnen et al. 2002), while tests conducted against $R$. microplus at 45 communally-grazed localities to the east of East London revealed emerging resistance to amitraz at two localities and resistance at a third (Ntondini et al. 2008). The possibility thus exists that $R$. decoloratus populations were being suppressed by the application of amitraz while the acaricide-resistant component of the R. microplus populations continued to flourish.

The relative abundance of $R$. microplus, in comparison to that of $R$. decoloratus on the farm 'Pumprock', implies that it is successfully displacing $R$. decoloratus also at this locality. Although $R$. decoloratus outnumbered R. microplus on the farm 'Shweme', future tick collections are likely to reveal encroachment by $R$. microplus also here.

Horak et al. (2009) commented fairly extensively on the likely reasons for the displacement of $R$. decoloratus by $R$. microplus. One of them being that $R$. microplus males, because of their slightly shorter life cycle than that of $R$. decoloratus, coupled with the fact that there are always more male ticks than female ticks (Horak et al. 1992, 2003), would not only mate with conspecific females but excess males would mate with those of $R$. decoloratus. Seventeen such couplings were observed in the present study, as were 13 incidents where $R$. microplus males were attached to engorged nymphs, which when dissected almost invariably proved to be the precursors of female ticks. The variations in morphological characters observed in larvae collected from the vegetation and grouped as $R$. (Boophilus) spp., with some of these characters seen as gradations between $R$. decoloratus and $R$. microplus, suggest that the eggs resulting 
from cross-matings may not always be sterile and that hybridization may indeed be possible. No adult hybrids exhibiting taxonomic features of both species were, however, collected.

The slightly shorter parasitic portion of the life cycle of R. microplus (Arthur and Londt 1973; Londt and Arthur 1975), coupled with the fact that within the eastern region of the Eastern Cape Province $R$. microplus larvae are present on vegetation during winter while those of $R$. decoloratus almost disappear (Nyangiwe et al. 2011), may result in $R$. microplus completing one more life cycle per year than $R$. decoloratus. This would also enhance its chances of displacing $R$. decoloratus.

Displacement of an indigenous species by a foreign species has implications for biodiversity. When, however this displacement occurs between tick species, there may also be serious implications for the transmission of disease. The indigenous tick $R$. decoloratus is the vector of Babesia bigemina, the causative organism of African redwater in cattle, while the invasive $R$. microplus transmits not only $B$. bigemina but also the more virulent Babesia bovis, the causative organism of Asiatic redwater in cattle (De Vos et al. 2004). The spread of $R$. microplus in South Africa has in several instances been accompanied by outbreaks of Asiatic redwater in regions in which only African redwater was recorded in the past. Such outbreaks are likely to increase as the tick expands its distribution range.

\section{Acknowledgements}

We express our thanks to the Eastern Cape Department of Agriculture for permission for Mr N. Nyangiwe to participate in the project. Our sincere thanks to Dr Roy Williams of the ARC-Onderstepoort Veterinary Institute for providing the maps and Heloise Heyne, also of the institute, for assistance with recording tick numbers. The participation of I.G. Horak in this project was made possible by a grant from the National Research Foundation of South Africa.

\section{References}

Anon. 2003. Sector profile: Agriculture-Livestock. Eastern Cape Development Corporation, Bhisho, South Africa. Anon. 2008. Agricultural Statistics. National Department of Agriculture, Pretoria, Republic of South Africa. 
Arthur, D.R and Londt, J.G.H. 1973. The parasitic life cycle of Boophilus decoloratus (Koch, 1844) (Acarina: Ixodidae). J. Ent. Soc. S. Afr. 36: 87-116.

Baker, J.A.F, Jordaan, J.O. and Robertson, W.D. 1981. A comparison of the resistance spectra to ixodicides of Boophilus decoloratus (Koch) and Boophilus microplus (Canestrini) in the Republic of South Africa and Transkei. In: Proceedings of an International Conference on Tick Biology and Control, Whitehead, G.B. \& Gibson, J.D. (eds.) pp. 103-108. Rhodes University, Grahamstown, South Africa, 27-29 January 1981. pp., 103-108. Rhodes University, Grahamstown, South Africa.

Baker, J.A.F. 1982. Some thoughts on resistance to ixodicides by ticks in South Africa. In: Proceedings of a Symposium on Ectoparasites of Cattle, 15 and 16 March 1982, pp. 52-67. South African Bureau of Standards, Pretoria, South Africa.

Davey, R.B. and Hilburn, L.R. 1991. Reduction in egg viability resulting from infestations on cattle of hybridized Boophilus ticks and B. microplus (Acari: Ixodidae) at various ratios. J. Med. Entomol. 28: 763-769.

De Castro, J.J. 1997. Sustainable tick and tick-borne disease control in livestock improvement in developing countries. Vet. Parasitol. 71: 77-97.

De Clercq, E.M., Vanwambeke, S.O., Sungirai, M., Adehan, S., Lokossou, R. and Madder, M. 2012. Geographic distribution of the invasive cattle tick Rhipicephalus microplus, a country-wide survey in Benin. Exp. Appl. Acarol. DOI 10.1007/s10493-012-9587-0.

De Matos, C., Sitoe, C., Neves, L., Nöthling, J.O. and Horak, I.G. 2009. The comparative prevalence of five tick species infesting cattle and goats in Maputo Province, Mozambique. Onderstepoort J. Vet. Res. 76: 201-208.

De Vos, A.J., De Waal, D.T. and Jackson, L.A. 2004. Bovine babesiosis. In: Infectious Diseases of Livestock, Coetzer and Tustin (eds), pp. 406-424. Oxford University Press, Cape Town.

Gothe, R. 1967. Ticks in the South African Zoological Survey Collection. Part XII. The genera Boophilus Curtice, 1891 and Margaropus Karsch, 1879. Onderstepoort J. Vet. Res. 34: 81-107.

Horak, I.G., Boomker, J., Spickett, A.M. and De Vos, V. 1992. Parasites of domestic and wild animals in South Africa. XXX. Ectoparasites of kudus in the eastern Transvaal Lowveld and the eastern Cape Province. Onderstepoort J. Vet. Res. 59: 259-273.

Horak, I.G. 1999. Parasites of domestic and wild animals in South Africa. XXXVII. Ixodid ticks on cattle on Kikuyu grass pastures and in Valley Bushveld in the Eastern Cape Province. Onderstepoort J. Vet. Res. 66: 175-184.

Horak, I.G., Gallivan, G.J., Braack, L.E.O., Boomker, J. and De Vos, V. 2003. Parasites of domestic and wild animals in South Africa. XLI. Arthropod parasites of impalas (Aepyceros melampus) in the Kruger National Park. Onderstepoort J. Vet. Res. 70: 131-163. 
Horak, I.G., Nyangiwe, N., De Matos, C. and Neves, L. 2009. Species composition and geographic distribution of ticks infesting cattle, goats and dogs in a temperate and in a subtropical region of south-east Africa. Onderstepoort J. Vet. Res. 76: 263-276.

Howell, C.J., Walker, J.B. and Nevill, E.M. 1978. Ticks, mites and insects infesting domestic animals in South Africa. Part 1. Descriptions and biology. Department of Agricultural Technical Services, Republic of South Africa, Science Bulletin no. 393.

Jongejan, F. and Uilenberg, G. 2004. The global importance of ticks. Parasitology 129 (Suppl): S3-S14.

Londt, J.G.H. and Arthur, D.R. 1975. The structure and parasitic life cycle of Boophilus microplus (Canestrini, 1888) in South Africa (Acarina: Ixodidae). J. Ent. Soc. S. Afr. 38: 321-340.

Lynen, G., Zeman, P., Bakuname, C., Di Giulio, G., Mtui, P., Sanka, P. and Jongejan, F. 2008. Shifts in the distributional ranges of Boophilus ticks in Tanzania: evidence that a parapatric boundary between Boophilus microplus and B. decoloratus follows climate gradients. Exp. Appl. Acarol. 44: 147-164.

Madder, M., Thys, E., Geysen, D., Baudoux, C. and Horak, I. 2007. Boophilus microplus ticks found in West Africa. Exp. Appl. Acarol. 43: 233-234.

Madder, M., Thys, E., Achi, L., Touré, A. and De Deken, R. 2011. Rhipicephalus (Boophilus) microplus: a most successful invasive tick species in West-Africa. Exp. Appl. Acarol. 53: 139-145.

Madder, M., Adehan, S., De Deken, R., Adehan, R. and Lokossou, R. 2012. New foci of Rhipicephalus microplus in West Africa. Exp. Appl. Acarol. 56: 385-390.

Masika, P.J., Sonandi, A. and Van Averbeke, W. 1997. Tick control by small-scale cattle farmers in the central Eastern Cape Province, South Africa. J. S. Afr. Vet. Ass. 68: 45-48.

Mason, C.A. and Norval, R.A.I. 1980. The ticks of Zimbabwe. I. The genus Boophilus. Zimbabwe Vet. J. 11: 36-43.

Mekonnen, S., Bryson, N.R., Fourie, L.J., Peter, R.J., Spickett, A.M., Taylor, R.J., Strydom, T. and Horak, I.G. 2002. Acaricide resistance profiles of single- and multi-host ticks from selected commercial and communal farming areas in the Eastern Cape and North-West provinces of South Africa. Onderstepoort J. Vet. Res. 69: 99-105.

Mekonnen, S., Bryson, N.R., Fourie, L.J., Peter, R.J., Spickett, A.M., Taylor, R.J., Strydom, T., Kemp, D.H. and Horak, I.G. 2003. A comparison of three methods to detect acaricide resistance in Boophilus decoloratus on dairy farms in the Eastern Cape Province, South Africa. J. S. Afr. Vet. Ass. 74: 1-44.

Mucina, L. and Rutherford, M.C. 2006. The vegetation of South Africa, Lesotho and Swaziland. Streltizia 19. South Africa National Biodiversity Institute, Pretoria.

Nyangiwe, N. and Horak, I.G. 2007. Goats as alternative hosts of cattle ticks. Onderstepoort J. Vet. Res. 74: 1-7. 
Nyangiwe, N., Goni, S., Hervé-Claude, L.P., Ruddat, I. and Horak, I.G. 2011. Ticks on pastures and on two breeds of cattle in the Eastern Cape province, South Africa. Onderstepoort J. Vet. Res. 78(1), Art. \#320, 9 pages. doi:10.4102/ojvr.v78i1.320.

Rechav, Y. 1982. Dynamics of tick populations (Acari: Ixodidae) in the eastern Cape Province of South Africa. J. Med. Entomol. 19: 679-700.

Tønnesen, M.H., Penzhorn, B.L., Bryson, N.R., Stoltsz, W.H. and Masibigiri, T. 2004. Displacement of Boophilus decoloratus by Boophilus microplus in the Soutpansberg region, Limpopo Province, South Africa. Exp. Appl. Acarol. 32: 199-208.

Ntondini, Z., Van Dalen, E.M.S.P. and Horak, I.G. 2008. The extent of acaricide resistance in 1-, 2- and 3-host ticks on communally grazed cattle in the eastern region of the Eastern Cape Province, South Africa. J. S. Afr. Vet. Ass. 79: 130-135.

Yeoman, G.H. and Walker, J.B. 1967. The ixodid ticks of Tanzania. A study of the zoogeoraphy of the Ixodidae of an east African country. Commonwealth Institute of Entomology, London and Reading. 